\title{
Pharmacological treatment of Parkinson's disease
}

\author{
G Arabia \\ From de Senectute: Age and Health Forum \\ Catanzaro, Italy. 5-7 December 2009
}

For the past 30 years levodopa (LD) has been the pharmacological standard of care for treating idiopathic Parkinson's disease (PD), a neurodegenerative disease of the central nervous system. LD is a pharmacologically inactive precursor, which is converted enzymatically to the neurotransmitter dopamine by a declining population of neurons in the substantia nigra, the most important site of the pathology of PD. Most patients experience a smooth, lasting response to small amounts of LD during the early years of treatment, but as the underlying disease gets worse, treatment-related problems arise. Motor fluctuations, which slowly emerge after 3-5 years of chronic LD therapy, gradually replace the smooth pattern of response, and more frequent dosing is required. Abnormal involuntary movements (dyskinesia), wearing-off of the motor response after a few hours, organic psychosis (confusion and hallucinations), and progressive loss of independence characterize the complication of the pharmacological treatment of PD. Despite its problems and the recent development of other antiparkinson drugs, LD remains the most effective pharmacologic agent available for the relief of symptoms in patients with PD. The use of dopamine agonists has been greatly encouraged in recent years. The main indication for their use is the initial therapy of patients with PD, particularly in younger patients. Several studies have reported that their early use may delay the onset of motor fluctuations and dyskinesia. The principal dopamine agonists are ergoline (bromocriptine, lisuride, pergolide, cabergoline) and non-ergoline (ropirinolo and pramipexole).

Apomorphine is a drug with a pharmacological profile comparable to that of dopamine. When administered subcutaneously in subjects with PD, apomorphine is able to quickly reverse the periods of motor off. It is therefore used in cases with severe motor fluctuations,

\footnotetext{
Institute of Neurology, Department of Medical Sciences, University "Magna
} Graecia" of Catanzaro, Catanzaro, Italy either by continuous infusion via a portable micropump with or by single bolus injections.

MAO and COMT are enzymes that metabolize dopamine in the central nervous system. Inhibitors of MAO and COMT are used to prolong the half-life of LD. Such drugs are represented by selegiline (MAO inhibitor) and tolcapone and entacapone (COMT inhibitors). The Italian guidelines suggest different treatment strategies according to the age of the patients with PD: for patients with early onset ( $<50$ years) monotherapy is recommended with dopamine agonists that may be associated with a low dose of LD; for patients aged 50 to 70 years monotherapy is recommended with dopamine agonists or with LD or association between the two treatments.

Published: 19 May 2010

doi:10.1186/1471-2318-10-S1-L30

Cite this article as: Arabia: Pharmacological treatment of Parkinson's disease. BMC Geriatrics 2010 10(Suppl 1):L30.

Submit your next manuscript to BioMed Central and take full advantage of:

- Convenient online submission

- Thorough peer review

- No space constraints or color figure charges

- Immediate publication on acceptance

- Inclusion in PubMed, CAS, Scopus and Google Scholar

- Research which is freely available for redistribution

Submit your manuscript at www biomedcentral.com/submit 